\title{
Isofocusing and Immunoelectrophoretic Studies of Soluble Eye Lens Proteins from Regenerated and Normally Developed Xenopus laevis
}

\author{
Samir K. Brahma \\ Department of Medical Anatomy and Embryology, The State University, Janskerkhof 3.4, \\ Utrecht, The Netherlands
}

(Received 27 August 1979, London)

\begin{abstract}
Soluble eye lens proteins from regenerated and normally developed 6-month-old Xenopus laevis ap/ap-mutant froglets were compared by thin-layer isoelectric focusing and microimmunoelectrophoresis. Larvae belonging to the same age group were reared through metamorphosis after the removal of the left lens at different larval stages as explained in the text. The results show that regenerating and normally developing lenses of similar ages have identical profiles of $\alpha-, \beta$ - and $\gamma$-crystallins and also identical antigenie determinants suggesting that gene expression for lens crystallins follows the same pathway in a regenerating lens as in a normally developing lens.

Key words: lentectomy; regenerate; ap/ap-mutant; soluble proteins; isoelectric focusing; immunoelectrophoresis.
\end{abstract}

\section{Introduction}

Freeman (1936) reported that in Xenopus laevis the inner cell layer of the outer cornea regenerates a lens following lentectomy only during the larval stages and that regenerative capacity is lost at metamorphosis when inner and outer cell layers of the larval cornea fuse to form adult cornea.

These regenerates synthesize $\alpha$-, $\beta$ - and $\gamma$-crystallins as do normally developed lenses although they develop from a different source (Campbell, 1965; Brahma and McDevitt, 1974; Reeve and Wild, 1978). They resemble normal lenses both macroscopically and microscopically, but it is not known whether the lens proteins from them include all the crystallin components found in normal lenses of the same age.

Campbell and Truman (1977) compared by immunoelectrophoresis the soluble lens proteins from regenerated and normally developing lens from individual Xenopus tadpoles after unilateral lentectomy. They reported that nine out of 17 regenerates showed a reduction in the numbers of $\beta$-crystallin arcs, and also that the concentration of $\beta$-crystallin appeared to be diminished as compared to control lenses, while the other eight were normal and they therefore suggested that the regulation of crystallin genes may not follow the normal ontogenic sequence. Since only a very small amount of soluble protein material is available from the individual tadpole lens, such results are highly probable when compared by immunoelectrophoresis alone as it is known that the formation of an immunoprecipitin are depends upon the concentration of antigens as well as upon the specificity of the antibody used.

A similar investigation has been undertaken to compare soluble proteins from normally developed and regenerated lenses of $\mathrm{a}^{\mathrm{p}} / \mathrm{a}^{\mathrm{p}}$-mutant Xenopus using thin-layer isoelectric focusing (IEF) on polyacrylamide gel. The animals, which belonged to the same age group, were lentectomized at different larval stages and reared through metamorphosis to 6-month-old frogs before the analysis. IEF was the method of choice for this study on account of its high resolving power and the proteins being resolved into sharp, narrow zones according to their isoelectric points ( $\mathrm{pI}$ values, 
Vesterberg, 1973). It has been shown that proteins whose pI's differ by as little as 0.005 of a pH unit can be successfully resolved (Righetti and Drysdale, 1974).

The lens proteins were also compared by immunoelectrophoresis against antibodies directed against wild type $(+/+)$ Xenopus total soluble lens proteins. The lens materials used in the present study were derived from a stock of spontaneous mutant of $X$. laevis discovered and described by Hoperskaya (1975). It shows a periodic albinism $\left(\mathrm{a}^{\mathrm{p}}\right)$ which is inherited as a typical Mendelian recessive trait.

Since the small quantity of material obtained made it impossible to compare a regenerated and a normally developed lens from the same animal even at 6 -months of age by IEF, the two groups of lenses were pooled scparately, and processed before the analysis.

\section{Materials and Methods}

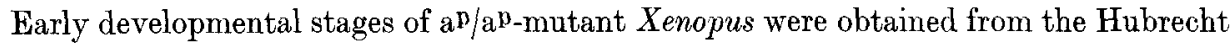
Laboratory, International Embryological Institute, in Utrecht and were reared in the author's laboratory at room temperature. Staging was carried out according to Nieuwkoop and Faber (1957). In the experiments reported here operations were performed at stages $49 / 50,51$ and 54 respectively.

The left lens from each larva was removed according to methods described earlier (Brahma and McDevitt, 1974), and each group of operated animals belonging to one of these three stages was reared separately through metamorphosis till they were 6 months old. From these young frogs, regenerated and normally developed lenses were removed under anaesthesia with MS 222, pooled separately, and disrupted by sonication in distilled water. The samples were then centrifuged, lyophilized and stored at $-20^{\circ} \mathrm{C}$ until needed.

The number of animals used for each stage was 8,10 and 10 respectively.

\section{Thin-layer isoelectric focusing (IEF)}

Thin-layer IEF was carried out at $4^{\circ} \mathrm{C}$ in $16 \times 25 \mathrm{~cm}$ gel plates containing $5 \%$ acrylamide and $2 \%$ Ampholyte (LKB Produktor AB, Sweden) having a $\mathrm{pH}$ range from 3.5 to $9 \cdot 0$ according to Brahma and Van der Starre (1976). To enable strict comparison to be made, $2 \%$ aqueous solutions were prepared from the lyophilized samples and $20 \mu \mathrm{l}$ was used from each. The samples were applied $1 \mathrm{~cm}$ apart and $0.5 \mathrm{~cm}$ from the anode. Two $10 \mu \mathrm{l}$ samples of myoglobin (Sigma) were run in the same gel $0.5 \mathrm{~cm}$ away from the cathodic and anodic ends respectively to act as a marker protein. The electrodes were $13 \mathrm{~cm}$ apart and the electrolyte buffers were $0.5 \% \mathrm{H}_{3} \mathrm{PO}_{4}$ and $0.5 \%$ ethylenediamine respectively.

Isofocusing was carried out with a constant voltage of $150 \mathrm{~V}$ until $16 \mathrm{hr}$, when this was raised to $250 \mathrm{~V}$. Six hr after the voltage increase, the myoglobin samples from the opposite sides met and fused. The run was then stopped. The $\mathrm{pH}$ of the gel was measured immediately at $4^{\circ} \mathrm{C}$ at points $1 \mathrm{~cm}$ apart along the sample migration axis, starting at the anodal end, using a flat membrane glass electrode (Ingold, Type 10403 3043), hooked to a digital pH meter (Radiometer PHM 62). The proteins were then precipitated with $14 \%$ TCA. The gels were then processed, stained with Coomassie Brilliant Blue R-250 (Weeke, 1973), and photographed.

\section{Immunoelectrophoresis}

The micro-immunoelectrophoretic method of Scheidegger (1955) was followed. In this series $10 \mu \mathrm{l}$ of the $2 \%$ solution made from each sample was tested against antibodies directed against $(+/+)$ wild Xenopus total soluble lens proteins. Each solution was run on a glass slide covered with $1.5 \%$ Difco Bacto agar in high resolution buffer (HRB) (Aronsson and Grönwall, 1957) at pH 8.9.

Each run was performed at $4^{\circ} \mathrm{C}$ in a Shandon Universal Electrophoresis Apparatus, 
MK 11 held at a constant voltage of $250 \mathrm{~V}$ for $90 \mathrm{~min}$. The immunodiffusion was allowed to continue for $24 \mathrm{hr}$ in a humid chamber at room temperature. The gels were then washed overnight in saline, dried and stained with Coomassie Brilliant Blue R-250.

\section{Results}

Thin-layer IEF of lens extracts from normally developed and regenerated froglets reared from larvae operated at different stages revealed no striking difference in the protein profiles or isoelectric points (pI values) for the $\alpha$-, $\beta$ - and $\gamma$-crystallin components. These crystallins were identified according to methods described earlier for the wild type $(+/+)$ Xenopus (Brahma and Bours, 1972). The pI value of $\alpha$-crystallin appeared to be $4 \cdot 78 ; \beta$-crystallin extended from $5 \cdot 85$ to $6 \cdot 85$; and $\gamma$-crystallin from 7.03 to 8.53 [Fig. l(a)-(f)].

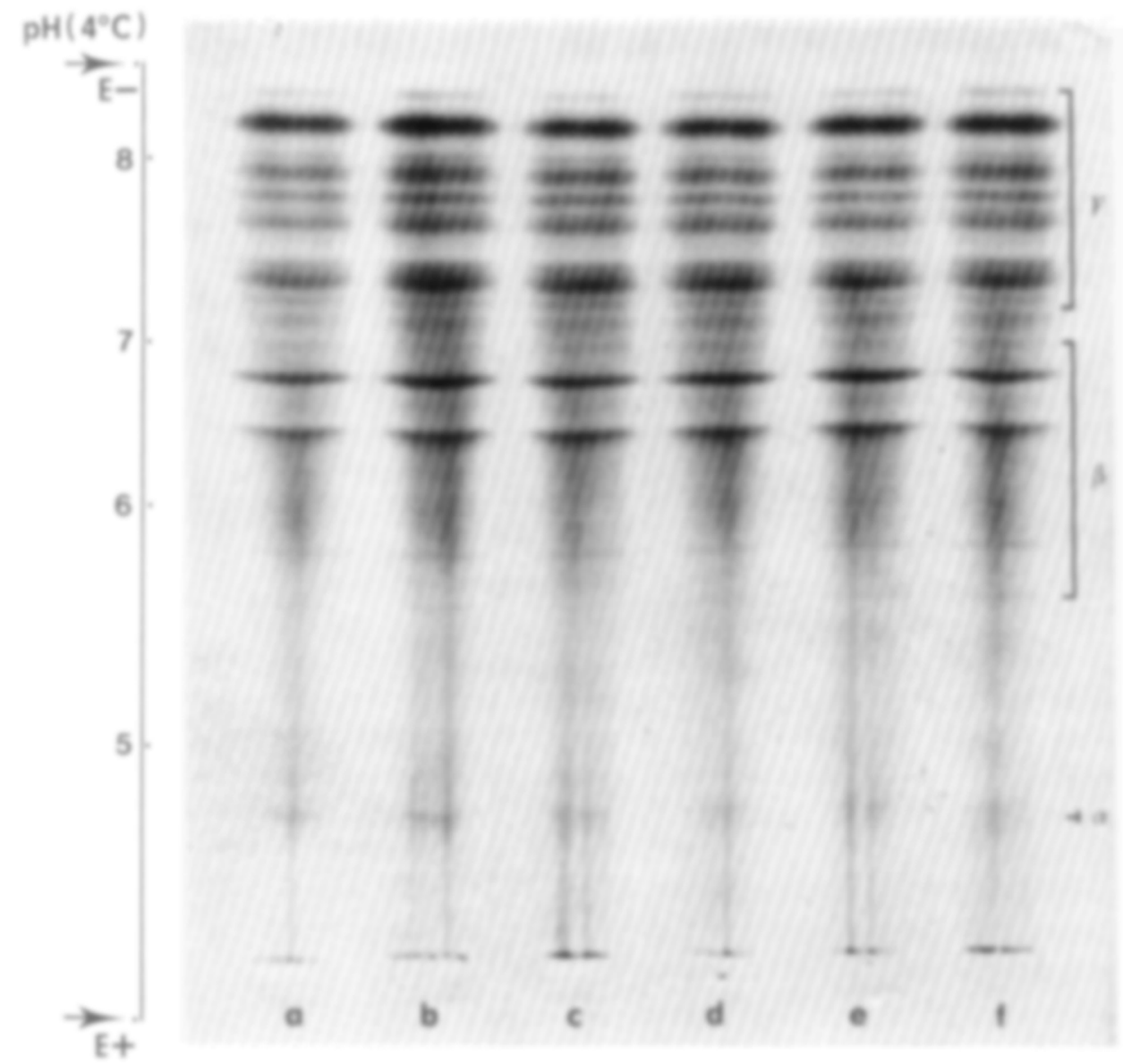

FIG. 1. Thin-layer isoelectric focusing of lens extracts from normally developed and regenerated 6-months-old a $/ \mathrm{a}^{\mathrm{p}}$-mutant Xenopus laevis frogs reared from stages $49 / 50,51$ and 54 respectively after the removal of the left lens. In this series a $\mathrm{pH}$ gradient from 3.5 to 9.0 was used. The electrodes were $13 \mathrm{~cm}$ apart. The $\mathrm{pH}$ was measured $1 \mathrm{~cm}$ apart along the sample migration axis at $4^{\circ} \mathrm{C}$ immediately after the run. After precipitation of the proteins in the gel with $14 \%$ TCA, the gel was processed and stainet with Coomassie Brilliant Biue R-250. It appears that the protein profiles and isoelectric points (pI) of $\alpha$-, $\beta$-and $\gamma$-crystallin components of the two samples are alike, a, $c$ and e represent samples from normal lens; while $b, d$ and $f$ are from regenerates belonging to the same age groups as a, $c$ and $e . E-$ and $\mathrm{E}$-represent the anodal and cathodal ends of the gel. $\mathrm{pH}$ of the gel is shown by the arabic numerals. The arrows represent the region where the electrodes were placed. 
Scanning of the photographs shown in Figure 1 with an integrated Chromoscan reflectance densitometer (Joyce, Loebl and Company, London) confirmed that the. pooled normal and regenerated lens extracts contained identical $\alpha-\beta$ - and $\gamma$-crystallins, and were qualitatively similar. Minor quantitative differences in the proportion of various components were observed, but these were not repeatable from experiment to experiment and this did not alter the immunoelectrophoretic profile. The patterns of antigenic determinants of the $\alpha$-, $\beta$ - and $\gamma$-crystallins from normally developed and regenerated lenses appeared identical by the immunoelectrophoresis [Fig. 2(a)-(f)].

\section{Discussion}

The results presented here from the IEF experiment show clearly that the lens crystallin profiles of normally developed and regenerated animals at 6 -months of age are identical in having the same number of $\alpha$-, $\beta$ - and $\gamma$-crystallin components with identical $\mathrm{pI}$ values. Densitometric scanning also did not show any qualitative difference between pooled normal and pooled regenerated lenses. Although a minor quantitative difference in the proportion of the different components was observed, these were not repeatable from between experiments and this minor difference did not alter the immunoelectrophoretic patterns of the two samples. It therefore seems unlikely that pooling has masked any real difference that could be detected if the lenses were analyzed individually.

In another series of experiments, lens proteins from stages 53, 58, metamorphosed. 5, 7 and 8 -months old and adult $\mathrm{a}^{\mathrm{p}} / \mathrm{a}^{\mathrm{p}}$-mutant Xenopus were analyzed by IEF (Brahma and McDevitt, in preparation). This study showed a predominance of the $\gamma$-crystallins at stage 53 with lesser amount of $\beta$ - and $\alpha$-crystallins. With increasing age, the percentage of $\beta$-, and $\alpha$-crystallins increased while that of the $\gamma$-crystallin decreased as in the wild type $(+/+)$ Xenopus (Brahma and Bours, 1972). In both these studies pooled lenses were used and the qualitative and quantitative differences between the crystallins due to age difference were not masked as a result of pooling.

The diameters of the normally developed and regenerated lenses at six months of age were not measured but most were of similar size although one or two regenerated lenses from each of the three groups appeared smaller. Since these were pooled with other lenses of the same age, it is not known if the smaller lenses had different protein profiles as reported by Doyle and Maclean (1978) in wild type $(+/+)$ Xenopus: larvae treated with propylthiouracil, a potent goitrogen. According to these authors, lens crystallin patterns are related to lens diameter rather than body size. Polansky and Benett (1973), on the other hand, reported that an increase in diameter in the Rana catesbeiana lens after thyroxine treatment was not associated with any change in the electrophoretic patterns of the crystallins.

The precise nature of the stimulus that leads to lens regeneration from the inner cell layer of the outer cornea following lentectomy in Xenopus larvae is not clearly understood. The importance of the eye cup and retina during such regeneration in vitro and in vivo is controversial (Freeman, 1963; Campbell and Jones, 1968; Waggoner, 1973; Reeve and Wild, 1977, 1978; Sologob, 1977). Reeve and Wild (1978) suggested that a stimulatory factor released by the eye cup initiates lens regeneration. The type of regeneration discussed here is different from the Wolffian regeneration found in the newt where a new lens develops via de-differentiation of a terminally differentiated tissue, the iris (Reyer, 1977), and can take place throughout the life span of the animal. In Xenopus, on the other hand, lens regeneration from the inner 
corneal cells is restricted to the larval stages and can occur only before differentiation of the adult cornea. It is therefore, not a metaplastic change.

Our immunofluorescence studies showed that the earliest positive reaction with antisera to $\gamma-, \alpha+\beta$ - and total lens crystallin antigens appeared later in normally developing $a_{a}^{\mathrm{p}} / \mathrm{a}^{\mathrm{p}}$-mutant than in the normally developing wild type $(+/+)(\mathrm{McDcvitt}$ and Brahma, 1979). Similar results were also obtained with regenerating lenses from the mutant (Brahma and McDevitt, in preparation). The sequential appearance of the crystallins in this mutant was also the same during lens regeneration and during normal lens development, i.e. $\beta$ - and $\gamma$-crystallins appearing first simultaneously followed by the $\alpha$-. It thus appears that the regulation of the crystallin genes in regeneration follows the normal ontogenic sequence.
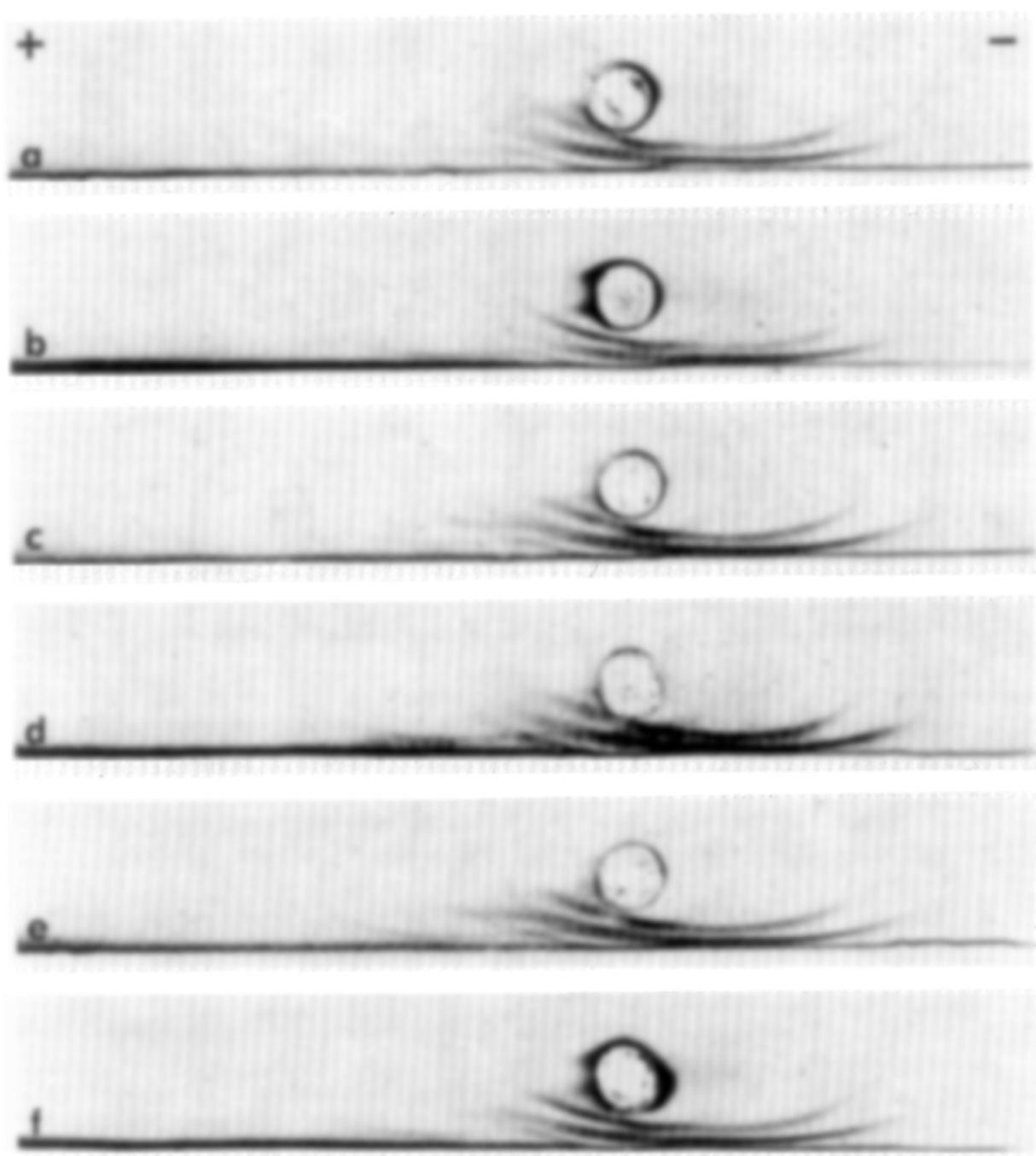

FIG, 2. Immunoelectrophoresis of lens extracts from normally developed and regenerated 6-monthsold ap/a $\mathrm{a}^{\mathrm{p}}$-mutant $X$. laevis frogs reared through metamorphosis from stages $49 / 50,51$ and 54 respectively after the removal of the left lens. These two kinds of lens extracts were tested against wild $(+l+) \dot{X}$. laevis total lens protein antiserum. a, $\mathrm{c}$ and e represent samples from normal lens; $b$, $d$ and $f$ are from regenerates belonging to the same age group as a, e and e. The immunoprecipitin lines were stained with Coomassie Brilliant Blue R-250. $+=$ anode; $-=$ cathode. 
The results presented here are not in agreement with those of Campbell and Truman (1977) who used only immunoelectrophoresis to compare protein antigens between normal and regenerating lenses in individual tadpoles after unilateral lentectomy. The absence of an immunoprecipitin line after the immunoelectrophoresis does not, however, indicate the absence of antigenic determinants. Such a line might escape detection if the relative concentration of the antigen to antibody is too low to allow formation of a zone of precipitation; or the antiserum titre against a particular antigen might be too low to produce a precipitin line. In view of very small amount of materials available from individual Xenopus such results are highly probable. It has been well documented in the developing chick where lens crystallins have been detected much later by immunoelectrophoresis than by immunofluorescent staining, radioimmunoprecipitation, radioimmunoassay, and combined IEF and radiography (Rabaey, 1962; Zwaan, 1963; Zwaan and Ikeda, 1968; Brahma and Van Doorenmaalen, 1973; Katoh and Yoshida, 1973; Shinohara, 1975; Brahma and Van der Starre, 1976). It therefore appears that meaningful comparison of lens protein is impossible using immunoelectrophoresis alone with such a small amount of material obtainable from single lens from a Xenopus tadpole.

\section{ACKNOWLEDGMENTS}

The author thanks Dr O. Hoperskaya for her permission to work on this material and the Hubrecht Laboratory, International Embryological Institute for the live material. It is a pleasure to acknowledge the help of Drs P. Janssen and A. J. Dursten for critically reviewing the manuscript. He also thanks Miss Aleid Weimar for the excellent technical help, Mr Th. Hulskes and Mr A. M. van Egeraat for the illustrations and Mrs J. Heidt-de Bruijn for typing the manuscript.

\section{REFERENCES}

Aronsson, T. and Grönwall, A. (1957). Improved separation of serum proteins in paper electrophoresis - a new electrophoresis buffer. Scand. J. Clin. Lab. Invest. 9, 338-41.

Brahma, S. K. and Van Doorenmaalen, W. J. (1971). Immunofluorescence studies of chick lens FISC and $\alpha$-crystallin antigens during lens morphogenesis and development. Ophthal. Res. 2, $344-57$.

Brahma, S. K. and Bours, J. (1972). Thin layer isoelectric focusing of soluble lens extracts from larval stages and adult Xenopus laevis. Exp. Eye Res. 13, 309-14.

Brahma, S. K. and McDevitt, D. S. (1974). Ontogeny and localization of the lens crystallins in Xenopus laevis lens regeneration. J. Embryol. Exp. Morph. 32, 78394.

Brahma, S. K. and Van der Starre, H. (1976). Studies on biosynthesis of soluble lens crystallin antigens in the chick by isoelectric focusing in thin-layer polyacrylamide gel. Exp. Cell Res. 97, $175-83$.

Campbell, J. C. (1965). An immuno-fluorescent study of lens regeneration in larval Xenopus laevis. J. Embryol. Exp. Morph. 13, 171-9.

Campbell, J. C. and Jones, K. W. (1968). The in vitro development of lens from cornca of larval Xenopus laevis. Develop. Biol. 17, 1-15.

Campbell, J. C. and Truman, D. E. S. (1977). Variation in differentiation in the regenerating lens of Xenopus lnevis. Exp. Eye Res. 25, 99-100.

Doyle, M. and Maclean, N. (1978). Biochemical changes in developmentally retarded Xenopus laevis larvae. 1. The lens crystallin transition. J. Embryol. Exp. Morph. 46, 215-25.

Freeman, G. (1963). Lens regeneration from cornea in Xenopus laevis. J. Exp. Zool. 154, 39-66.

Hoperskaya, O. A. (1975). The development of animals homozygous for a mutation causing periodic albinism (a ${ }^{\mathfrak{p})}$ in Xenopus laevis. J. Embryol. Exp. Morph. 34, 253-64.

Katoh, A. and Yoshida, K. (1973). Delta crystallin synthesis during chick lens differentiation. Exp. Eye Res. 15, 353-60.

McDevitt, D. S. and Brahma, S. K. (1979). Embryonic appearance of $\alpha$-, $\beta$ - and $\gamma$-crystallins in the periodic albinism (ap) mutant of Xenopus laevis. Differentiation 14, 107-12. 
Nieuwkoop, P. D. and Faber, J. (1956). Normal Table of Xenopus laevis (Daudin). North Holland Publishing Company, Amsterdam.

Polansky, J. R. and Benetl, T. P. (1973). Alterations in physical paramelers and proteins of lenses from Rana catesbeiana during development. Devel. Biol. 33, 380-408.

Rabaey, M. (1962). Electrophoretic and immunoelectrophoretic studies on the soluble proteins in the developing lens of birds. Exp. Eye Res. 1, 310-16.

Reeve, J. G. and Wild, A. E. (1977). Lens regeneration from cornea in tail ectopic eyes of Xenopus. laevis tadpoles. Experientia 33, 1210-11.

Reeve, J. G. and Wild, A. E. (1978). Lens regeneration from cornea of larval Xenopus laevis in presence of the lens. J. Embryol. Exp. Morph. 48, 205-14.

Reyer, R. W. (1977). The amphibian eye. Development and regeneration. Handbook of Sensory Physiology 7/5. The Visual System in Vertebrates (Ed. Crescitelli. F.). Springer Verlag. Berlin. Heidelberg.

Righetti, P. G. and Drysdale, J. W. (1974). Isoelectric focusing in gels. J. Chromatography 98, $271-321$.

Scheidegger, J. J. (1955). Une microméthode de l'immuno-électrophorese. Int. Arch. Allergy 7, 103-10.

Shinoshara, T. (1975). A radioimmunoassay for the detection of delta crystallin in chick lens differentiation. Develop. Growth Differ. 17, 127-42.

Sologob, A. A. (1977). Mechanism of repression and derepression of artificial transformation of pigmented epithelium into retina in Xenopus laevis. Wilhelm Roux' Archives 182, 277-91.

Vesterberg, 0. (1973). Physicochemical properties of the carrier ampholytes and some biochemical applications. Ann. N.Y. Acad. Sci. 209, 23-33.

Waggoner, P. R. (1973). Lens differentiation from the cornea following lens extirpation or cornea transplantation in Xenopus laevis. J. Exp. Zool. 186, 97-110.

Weeke, B. (1973). General remarks on principles, equipment, reagent and procedures. Scand. J. Immunol. 2 (Suppl.), 15-35.

Zwaan, J. (1963). Inumunochemical analysis of the eye lens during development. Ph.D. Thesis. University of Amsterdam, The Netherlands.

Zwaan, J. and Ikeda, A. (1968). Macromolecular events during differentiation of the ehick eye lens. Exp. Eye Res. 7, 301-11. 